\title{
Investigation into the use of a water curtain over openings to prevent fire spread
}

\author{
Matt Turco $^{1}$, Paul Lhotsky ${ }^{2}$ and George Hadjisophocleous ${ }^{1}$ \\ ${ }^{1}$ Department of Civil and Environmental Engineering, Carleton University, Ottawa, ON, Canada \\ ${ }^{2}$ CIVELEC Consultants Inc. Montreal, Quebec
}

\begin{abstract}
This paper presents the results of several full-scale experiments to study heat radiation attenuation and shielding using sprinklers to create a water curtain between a compartment fire and a target wall. This work builds on the concept that water absorbs and scatters heat radiation and applies it as a shielding mechanism, which can be used to protect personnel and property exposed to an opening during a compartment fire. The purpose of the study is to determine the effectiveness of a water curtain created using sprinkler heads in attenuating the heat flux from flames exiting a compartment fire, shielding the target wall and preventing fire spread. The results show that the water curtain reduces heat flux to the target wall which may allow for decreasing the building distance from the property line. Heat fluxes along the target wall are compared to heat fluxes required for the piloted ignition of wood products. The effects of fire size, sprinkler system flow rate, and separation distance to the target wall are discussed.
\end{abstract}

\section{INTRODUCTION}

During a compartment fire radiation heat exiting the compartment opening poses a risk to adjacent properties. If the heat flux leaving the compartment exceeds the heat flux required for piloted ignition of the building materials the fire could spread from the compartment to the adjacent properties. The radiation heat flux is affected by many factors such as the flames exiting the compartment, compartment size, and opening size. Several studies have been completed on this [1-6]. In order to reduce the radiation heat flux leaving a compartment this study utilized a water curtain created using sprinklers placed over the opening. Cheng [6] studied heat radiation exiting a compartment and impinging on an adjacent target wall. This was done using a built compartment with two different fire sources for comparison. The effect of water droplets on the suppression of fire and as a shielding mechanism has been the subject of many studies [7-17]. Kermida [7] found the ability of water droplets to suppress fires is due to the following four methods; gas phase cooling, oxygen dilution, fuel bed cooling, and radiation attenuation. This study utilized the ability of water to attenuate radiation to reduce the heat flux leaving the compartment. The main mechanisms involved are radiation absorption and scattering by water droplets [7-13]. Chow [14] and Choi [15] performed similar experiments in order to determine if a room could be protected from a fire in an adjacent room with the use of a water curtain. Studies have investigated the ability of water curtains as a shield to protect property $[11,12,17,18]$. This research was undertaken to determine if the

This is an Open Access article distributed under the terms of the Creative Commons Attribution License 2.0, which permits unrestricted use, distribution, and reproduction in any medium, provided the original work is properly cited. 


\section{MATEC Web of Conferences}

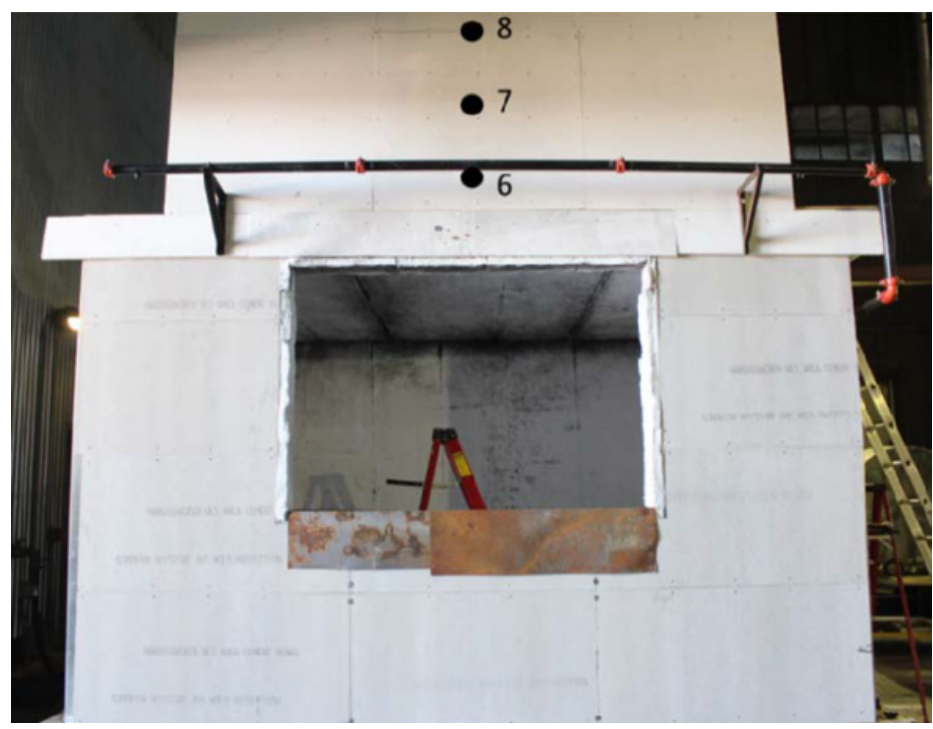

Figure 1. Compartment with sensor locations.

use of a water curtain over an opening can be utilized to add another factor of safety to limit the distance of adjacent properties. The main objective of this research is to determine the effectiveness of a water curtain at attenuating heat radiation leaving a compartment to prevent fire spread to adjacent properties and to model the effect that the water curtain has on the radiation exiting the compartment in order to develop a simple mathematical model for radiation that accounts for the reduction caused by the water curtain.

\section{EXPERIMENTAL SETUP}

To address this issue, a series of 24 full scale experiments to investigate the use of a water curtain over a compartment opening to prevent fire spread to adjacent properties was performed at the Carleton University Fire Research Lab. The tests utilized a small compartment and a target wall which can be moved to a desired distance away from the compartment. For the fire, propane burners placed inside the compartment were used.

\subsection{Compartment design}

Figure 1 shows the compartment, built using steel studs protected with half inch cement board and two inches of fire resistant Fibrefrax insulation on all interior surfaces. The floor was layered with fire resistant bricks which supported the propane burners. The compartment was $3 \mathrm{~m}$ by $4 \mathrm{~m}$ by $3 \mathrm{~m}$ high with an opening of $2 \mathrm{~m}$ by $1.5 \mathrm{~m}$ high. The front wall extended $3 \mathrm{~m}$ above the compartment. The front face of the compartment was protected with a layer of cement board.

\subsection{Water curtain}

To create the water curtain 3 standard pendent $(\mathrm{k}=5.6)$ sprinklers were used outside of the compartment at spacing's of $2 \mathrm{~m}$. The sprinklers were placed $0.46 \mathrm{~m}$ above the opening and $0.3 \mathrm{~m}$ away from the front of the compartment. The sprinklers were centred in the middle of the compartment opening. A pump 


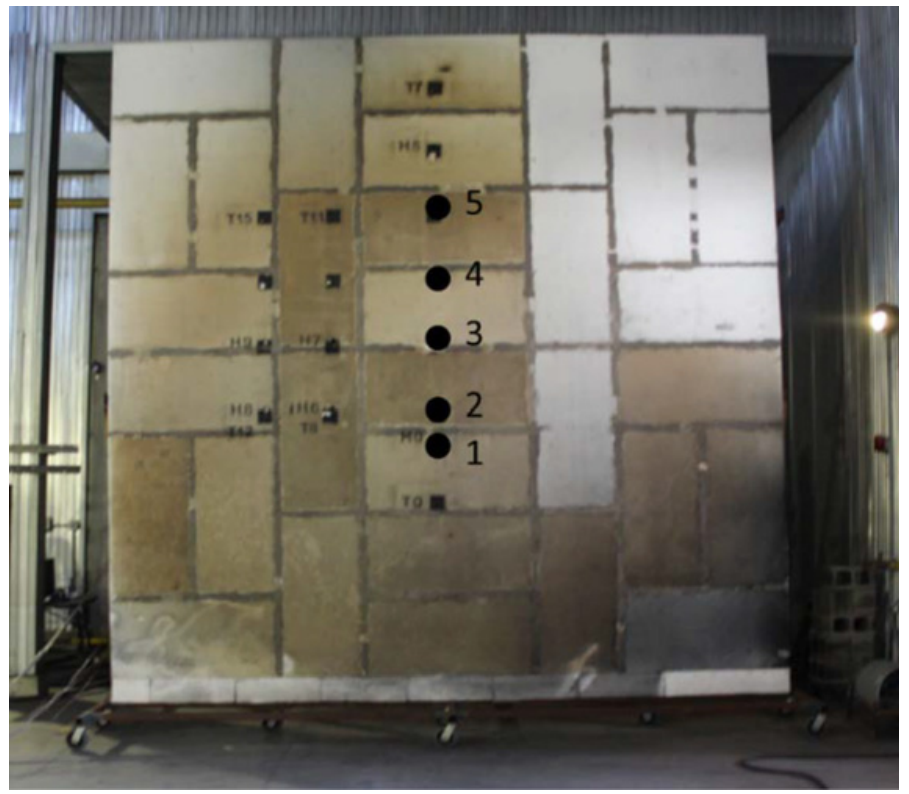

Figure 2. Target wall with sensor locations.

placed within a reservoir inside the lab provided water to the sprinkler system. The flow rate of the sprinklers was monitored using a flow meter and a pressure gauge located along the pipe next to the pump. The flow was controlled using a valve next to the flow meter.

\subsection{Propane burners}

To create the fire, three propane burners were placed in the centre of the compartment $0.06 \mathrm{~m}$ above the floor. The pipes for the burners enter the compartment through openings at the rear of the compartment which were sealed after the burners were installed. The propane burners were controlled using valves placed along the pipes outside the rear of the compartment and monitored using pressure gauges and a propane flow meter. This ensured that a constant fire heat release rate was produced and maintained during the tests.

\subsection{Target wall}

Figure 2 shows the target wall constructed of a wood frame built upon rollers with a layer of cement board covering the front face. The wall was $4.9 \mathrm{~m}$ by $4.9 \mathrm{~m}$ and could be moved to the desired distance away from the compartment.

\subsection{Instrumentation}

Five heat flux gauges and five thermocouples were placed along the target wall beginning $2.2 \mathrm{~m}$ above the floor in line with the centre of the compartment opening. The next sensor was $0.2 \mathrm{~m}$ above the first and subsequent sensors were spaced at $0.5 \mathrm{~m}$. Three heat flux gauges and thermocouples were placed on the front wall extending above the opening to the compartment. The first sensor on the extension wall was $0.55 \mathrm{~m}$ above the opening and subsequent sensors were spaced at $0.5 \mathrm{~m}$. The heat 
Table 1. Heat flux $\left(\mathrm{kW} / \mathrm{m}^{2}\right)$ results for the 2-MW fire tests at a separation distance of $3 \mathrm{~m}$.

\begin{tabular}{|c|c|c|c|c|c|c|c|}
\hline Sensor Location & $0 \mathrm{~L} / \mathrm{min}$ & $57 \mathrm{~L} / \mathrm{min}$ & \% Reduction & $76 \mathrm{~L} / \mathrm{min}$ & \% Reduction & $91 \mathrm{~L} / \mathrm{min}$ & \% Reduction \\
\hline 1 & 8.20 & 3.20 & 0.61 & 3.40 & 0.59 & 4.10 & 0.50 \\
\hline 2 & 8.20 & 3.90 & 0.52 & 3.30 & 0.60 & 3.80 & 0.54 \\
\hline 3 & 8.20 & 4.60 & 0.44 & 4.40 & 0.46 & 4.40 & 0.46 \\
\hline 4 & 7.50 & 4.60 & 0.39 & 4.50 & 0.40 & 4.50 & 0.40 \\
\hline 5 & 5.10 & 3.10 & 0.39 & 3.00 & 0.41 & 3.80 & 0.25 \\
\hline Target Wall Average & 7.44 & 3.88 & 0.47 & 3.72 & 0.49 & 4.12 & 0.43 \\
\hline 6 & 13.30 & 3.40 & 0.74 & 3.10 & 0.77 & 2.80 & 0.79 \\
\hline 7 & 9.30 & 2.90 & 0.69 & 2.70 & 0.71 & 2.10 & 0.77 \\
\hline 8 & 6.30 & 3.30 & 0.48 & 2.90 & 0.54 & 2.20 & 0.65 \\
\hline Façade Wall Average & 9.63 & 3.20 & 0.64 & 2.90 & 0.67 & 2.37 & 0.74 \\
\hline
\end{tabular}

flux gauges used were Gardon Gauges accurate to within $+/-3 \%$. The heat flux gauges were calibrated by the Medtherm Corporation in compliance with ISO/IEC 17025, ANSI/NCSL Z540-1 and MIL-STD45662A to Medtherm PI-20 with traceability to the National Institute of Standards and Technology. The thermocouples used were standard K-type thermocouples which are accurate to within $+/-0.75 \%$.

\subsection{Test series}

Two test series were run, one with a separation distance between the compartment and the target wall at $3 \mathrm{~m}$ and one at $4 \mathrm{~m}$. The test series considered fires with sizes of 2-MW, 3-MW, and 4-MW. Tests ran until the heat flux readings along the target wall reached steady state. Tests initially ran without the use of sprinklers in order to determine a baseline heat flux along the target wall and then the sprinklers were activated and run at flow rates of $57 \mathrm{~L} / \mathrm{min}(15 \mathrm{gpm}), 76 \mathrm{~L} / \mathrm{min}(20 \mathrm{gpm})$, and $91 \mathrm{~L} / \mathrm{min}(24 \mathrm{gpm})$ per sprinkler (Note that flow is in US gallon per minute).

\section{RESULTS}

\subsection{First test series: $3 \mathrm{~m}$ separation distance}

The heat flux results for the 2-MW fire at $3 \mathrm{~m}$ are presented in Table 1 . The initial average heat flux experienced by the target wall when no sprinklers were active was $7.44 \mathrm{~kW} / \mathrm{m}^{2}$, which is below the threshold for piloted ignition of wood products. The introduction of the water curtain decreased the heat flux readings on the target wall for all flow rates to below $4.6 \mathrm{~kW} / \mathrm{m}^{2}$. On the façade wall the heat flux was initially between $6.3 \mathrm{~kW} / \mathrm{m}^{2}$ and $13.3 \mathrm{~kW} / \mathrm{m}^{2}$. Use of the sprinklers at all flow rates caused the average heat flux to drop to below $3.2 \mathrm{~kW} / \mathrm{m}^{2}$, substantially lower than the initial values as well as the critical heat flux for piloted ignition of wood products.

The heat flux results for the 3-MW fire at $3 \mathrm{~m}$ are presented in Table 2. The average heat flux along the target wall was $13.6 \mathrm{~kW} / \mathrm{m}^{2}$ initially, greater than that required for piloted ignition of wood products. Reduction of the heat fluxes with the use of sprinklers increased with increasing sprinkler flow rate, lowering the initial heat flux below the critical value. On the facade wall the heat flux was initially between $10 \mathrm{~kW} / \mathrm{m}^{2}$ and $25 \mathrm{~kW} / \mathrm{m}^{2}$. As with the target wall, the front wall extension saw a similar decrease in the average heat flux with every increase in sprinkler flow rate.

The heat flux results for the 4-MW fire at $3 \mathrm{~m}$ are presented in Table 3. The initial average heat flux experienced by the target wall was $23.3 \mathrm{~kW} / \mathrm{m}^{2}$. The use of the water curtain showed a similar pattern to that seen for the 3-MW fire tests with each increase in flow rate having a larger impact on reducing the average heat flux. Heat fluxes were greater than the critical heat flux but it should be noted that the water curtain was wetting the target wall. During real fire events the water curtain is predicted to prevent sparks from reaching the adjacent properties. On the facade wall the heat flux was initially between 
Table 2. Heat flux $\left(\mathrm{kW} / \mathrm{m}^{2}\right)$ results for the 3-MW fire tests at a separation distance of $3 \mathrm{~m}$.

\begin{tabular}{|c|c|c|c|c|c|c|c|}
\hline Sensor Location & $0 \mathrm{~L} / \mathrm{min}$ & $57 \mathrm{~L} / \mathrm{min}$ & \% Reduction & $76 \mathrm{~L} / \mathrm{min}$ & \% Reduction & $91 \mathrm{~L} / \mathrm{min}$ & \% Reduction \\
\hline 1 & 14.5 & 13 & 0.10 & 9.6 & 0.34 & 7.6 & 0.48 \\
\hline 2 & 13.9 & 14.5 & -0.04 & 9.4 & 0.32 & 7 & 0.50 \\
\hline 3 & 15.8 & 15.3 & 0.03 & 10.8 & 0.32 & 7.7 & 0.51 \\
\hline 4 & 13.8 & 14.4 & -0.04 & 10.6 & 0.23 & 7.3 & 0.47 \\
\hline 5 & 10.2 & 9.5 & 0.07 & 7.4 & 0.27 & 5.4 & 0.47 \\
\hline Target Wall Average & 13.64 & 13.34 & 0.02 & 9.56 & 0.30 & 7.00 & 0.49 \\
\hline 6 & 24.8 & 12 & 0.52 & 6.8 & 0.73 & 4.6 & 0.81 \\
\hline 7 & 15.6 & 10.7 & 0.31 & 5.7 & 0.63 & 3.6 & 0.77 \\
\hline 8 & 10.9 & 10.8 & 0.01 & 5.8 & 0.47 & 3.5 & 0.68 \\
\hline Façade Wall Average & 17.10 & 11.17 & 0.28 & 6.10 & 0.61 & 3.90 & 0.75 \\
\hline
\end{tabular}

Table 3. Heat flux $\left(\mathrm{kW} / \mathrm{m}^{2}\right)$ results for the 4-MW fire tests at a separation distance of $3 \mathrm{~m}$.

\begin{tabular}{|c|c|c|c|c|c|c|c|}
\hline Sensor Location & $0 \mathrm{~L} / \mathrm{min}$ & $57 \mathrm{~L} / \mathrm{min}$ & \% Reduction & $76 \mathrm{~L} / \mathrm{min}$ & \% Reduction & $91 \mathrm{~L} / \mathrm{min}$ & \% Reduction \\
\hline 1 & 25.1 & 18.8 & 0.25 & 15.5 & 0.38 & 13.8 & 0.45 \\
\hline 2 & 23.8 & 20.8 & 0.13 & 15.7 & 0.34 & 13.2 & 0.45 \\
\hline 3 & 26.6 & 20.1 & 0.24 & 17 & 0.36 & 14 & 0.47 \\
\hline 4 & 23.4 & 18 & 0.23 & 15.8 & 0.32 & 13.1 & 0.44 \\
\hline 5 & 17.4 & 12.6 & 0.28 & 11.2 & 0.36 & 9.1 & 0.48 \\
\hline Target Wall Average & 23.26 & 18.06 & 0.23 & 15.04 & 0.35 & 12.64 & 0.46 \\
\hline 6 & 41.2 & 18.3 & 0.56 & 11.2 & 0.73 & 8.6 & 0.79 \\
\hline 7 & 22.2 & 15.7 & 0.29 & 9.2 & 0.59 & 5.7 & 0.74 \\
\hline 8 & 16.7 & 14.8 & 0.11 & 9.8 & 0.41 & 5.4 & 0.68 \\
\hline Façade Wall Average & 26.70 & 16.27 & 0.32 & 10.07 & 0.58 & 6.57 & 0.74 \\
\hline
\end{tabular}

Table 4. Heat flux $\left(\mathrm{kW} / \mathrm{m}^{2}\right)$ results for the 2-MW fire tests at a separation distance of $4 \mathrm{~m}$.

\begin{tabular}{|c|c|c|c|c|c|c|c|}
\hline Sensor Location & $0 \mathrm{~L} / \mathrm{min}$ & $57 \mathrm{~L} / \mathrm{min}$ & \% Reduction & $76 \mathrm{~L} / \mathrm{min}$ & \% Reduction & $91 \mathrm{~L} / \mathrm{min}$ & \% Reduction \\
\hline 1 & 7.3 & 6.7 & 0.08 & 6.3 & 0.14 & 5.9 & 0.19 \\
\hline 2 & 6.7 & 6 & 0.10 & 6 & 0.10 & 5.4 & 0.19 \\
\hline 3 & 6.8 & 6.3 & 0.07 & 6 & 0.12 & 5.5 & 0.19 \\
\hline 4 & 6.6 & 5.5 & 0.17 & 5.4 & 0.18 & 5.1 & 0.23 \\
\hline 5 & 4.7 & 4.3 & 0.09 & 4.1 & 0.13 & 3.8 & 0.19 \\
\hline Target Wall Average & 6.42 & 5.76 & 0.10 & 5.56 & 0.13 & 5.14 & 0.20 \\
\hline 6 & 7.7 & 4.6 & 0.40 & 4.1 & 0.47 & 2.1 & 0.73 \\
\hline 7 & 7 & 4.9 & 0.30 & 2.3 & 0.67 & 1.2 & 0.83 \\
\hline 8 & 6.3 & 5.1 & 0.19 & 2.5 & 0.60 & 0.24 & 0.96 \\
\hline Façade Wall Average & 7.00 & 4.87 & 0.30 & 2.97 & 0.58 & 1.18 & 0.84 \\
\hline
\end{tabular}

$16 \mathrm{~kW} / \mathrm{m}^{2}$ and $42 \mathrm{~kW} / \mathrm{m}^{2}$. The use of the sprinklers caused greater drops in the average heat flux with increasing in sprinkler flow rates.

\subsection{Second test series: $4 \mathrm{~m}$ separation distance}

The heat flux results for the 2-MW fire at $4 \mathrm{~m}$ are presented in Table 4 . The initial average heat flux experienced by the target wall when no sprinklers were active was $6.4 \mathrm{~kW} / \mathrm{m}^{2}$, which is below the threshold for piloted ignition of wood products as it was for the previous 2-MW fire tests. On the façade wall the heat flux was initially between $6.3 \mathrm{~kW} / \mathrm{m}^{2}$ and $7.7 \mathrm{~kW} / \mathrm{m}^{2}$. Use of the sprinklers at all flow rates caused the average heat flux to drop.

The heat flux results for the 3-MW fire at $4 \mathrm{~m}$ is presented in Table 5. The average heat flux along the target wall was $13.7 \mathrm{~kW} / \mathrm{m}^{2}$ initially, greater than that required for piloted ignition of wood products. On the facade wall the heat flux was initially between $13 \mathrm{~kW} / \mathrm{m}^{2}$ and $19 \mathrm{~kW} / \mathrm{m}^{2}$. The use of the water 
Table 5. Heat flux $\left(\mathrm{kW} / \mathrm{m}^{2}\right)$ results for the 3-MW fire tests at a separation distance of $4 \mathrm{~m}$.

\begin{tabular}{|c|c|c|c|c|c|c|c|}
\hline Sensor Location & $0 \mathrm{~L} / \mathrm{min}$ & $57 \mathrm{~L} / \mathrm{min}$ & \% Reduction & $76 \mathrm{~L} / \mathrm{min}$ & \% Reduction & $91 \mathrm{~L} / \mathrm{min}$ & \% Reduction \\
\hline 1 & 14.8 & 9.8 & 0.34 & 10.3 & 0.30 & 9.9 & 0.33 \\
\hline 2 & 14 & 9 & 0.36 & 9.6 & 0.31 & 9.2 & 0.34 \\
\hline 3 & 15.3 & 9.8 & 0.36 & 10.2 & 0.33 & 9.6 & 0.37 \\
\hline 4 & 14.2 & 9.1 & 0.36 & 9.9 & 0.30 & 9.6 & 0.32 \\
\hline 5 & 10.3 & 7.1 & 0.31 & 7.6 & 0.26 & 7.4 & 0.28 \\
\hline Target Wall Average & 13.72 & 8.96 & 0.34 & 9.52 & 0.30 & 9.14 & 0.33 \\
\hline 6 & 18.4 & 6.9 & 0.63 & 5 & 0.73 & 3.9 & 0.79 \\
\hline 7 & 16.7 & 7.9 & 0.53 & 5.1 & 0.69 & 4.3 & 0.74 \\
\hline 8 & 13.1 & 7.8 & 0.40 & 4 & 0.69 & 3.2 & 0.76 \\
\hline Façade Wall Average & 16.07 & 7.53 & 0.52 & 4.70 & 0.71 & 3.80 & 0.76 \\
\hline
\end{tabular}

Table 6. Heat flux $\left(\mathrm{kW} / \mathrm{m}^{2}\right)$ results for the 4-MW fire tests at a separation distance of $4 \mathrm{~m}$.

\begin{tabular}{|c|c|c|c|c|c|c|c|}
\hline Sensor Location & 0 L/min & $57 \mathrm{~L} / \mathrm{min}$ & \% Reduction & $76 \mathrm{~L} / \mathrm{min}$ & \% Reduction & $91 \mathrm{~L} / \mathrm{min}$ & \% Reduction \\
\hline 1 & 20.9 & 16.7 & 0.20 & 15.9 & 0.24 & 14.4 & 0.31 \\
\hline 2 & 19.9 & 14.8 & 0.26 & 15.2 & 0.24 & 13.6 & 0.32 \\
\hline 3 & 21.2 & 15.6 & 0.26 & 15.7 & 0.26 & 14.2 & 0.33 \\
\hline 4 & 19.8 & 14.8 & 0.25 & 14.6 & 0.26 & 13.4 & 0.32 \\
\hline 5 & 14.4 & 11.4 & 0.21 & 11.2 & 0.22 & 10.1 & 0.30 \\
\hline Target Wall Average & 19.24 & 14.66 & 0.24 & 14.52 & 0.24 & 13.14 & 0.32 \\
\hline 6 & 39.4 & 13.9 & 0.65 & 10.7 & 0.73 & 7.6 & 0.81 \\
\hline 7 & 33.2 & 12 & 0.64 & 10.3 & 0.69 & 7.9 & 0.76 \\
\hline 8 & 22.9 & 9.6 & 0.58 & 7.6 & 0.67 & 6 & 0.74 \\
\hline Façade Wall Average & 31.83 & 11.83 & 0.62 & 9.53 & 31.83 & 11.83 & 0.62 \\
\hline
\end{tabular}

curtain caused a decrease in heat flux readings for both the target wall and the façade wall to below critical values.

The heat flux results for the 4-MW fire at $4 \mathrm{~m}$ is presented in Table 6 . The initial average heat flux experienced by the target wall was $19.2 \mathrm{~kW} / \mathrm{m}^{2}$. Similar to the 4-MW fire at $3 \mathrm{~m}$ separation, the heat fluxes were greater than the critical heat flux but no sparks were getting through the water curtain. On the facade wall the heat flux was initially between $22 \mathrm{~kW} / \mathrm{m}^{2}$ and $40 \mathrm{~kW} / \mathrm{m}^{2}$. Use of the sprinklers caused the heat flux readings to decrease.

\subsection{Discussion}

Based on the 2-MW fire tests for both separation distances, $3 \mathrm{~m}$ and $4 \mathrm{~m}$, the initial heat fluxes along the target wall were found to be below the critical heat flux required for piloted ignition of wood products. With the sprinkler flow the heat flux reductions for both distances were found to be similar for all flow rates meaning that increasing the water flow rates had minimal impact on the attenuation after the minimum flow rate test. The results from the façade wall sensors showed that the heat fluxes above the opening were varied due to the hot gases exiting the compartment. With the introduction of the sprinklers all heat fluxes dropped to well below the critical heat flux.

Based on the 3-MW fire tests the initial heat fluxes were greater than the critical heat flux for piloted ignition of wood products. With the sprinkler flow all heat fluxes fell below the critical heat flux for the 4-m tests but required a larger flow rate to bring the 3-m separation distance tests to below the critical heat flux.

Along the façade wall the initial heat fluxes were greater than the critical heat flux but all fell below the critical heat flux with the sprinkler water flow. A significant increase in attenuation was seen with the increase in the sprinkler flow rates for both separation distances.

The initial heat flux results of the 4-MW fire tests were much greater than the critical heat flux for piloted ignition of wood products. The sprinkler water flow failed to bring the heat fluxes below the 
Table 7. Average calculated compartment temperatures based on the baseline test results.

\begin{tabular}{cc}
\hline Test Series & Average Compartment Temperature $\left(\mathrm{K} /{ }^{\circ} \mathbf{C}\right)$ \\
\hline 2-MW @ 3-m & $1175(902)$ \\
\hline 2-MW @ 4-m & $1281(1008)$ \\
\hline 3-MW @ 3-m & $1223(950)$ \\
\hline 3-MW @ 4-m & $1389(1116)$ \\
\hline 4-MW @ 3-m & $1349(1076)$ \\
\hline 4-MW @ 4-m & $1463(1190)$ \\
\hline
\end{tabular}

critical heat flux but they were brought low enough to avoid spontaneous combustion. Even though the heat fluxes were above the critical value, the critical value is conservative and requires a spark or flame to be in close proximity to the target wall. With the use of the sprinklers, sparks and flames were unable to penetrate the water curtain and during the 3-m separation tests the water curtain was wetting the wall. The use of sprinklers caused uniform reductions to the heat fluxes for both separation distances. Along the façade wall initial heat fluxes were greater than the critical heat flux but fell below the critical heat flux with the larger flow rate sprinklers. A significant increase in attenuation was seen with the increase in the sprinkler flow rates for the 3-m separation distance with a smaller increase for the 4-m separation distance.

The attenuation along the target wall was found to be less effective for the larger separation distance. The heat fluxes for all the experiments were lowered to acceptable ranges such that flame spread could be avoided, protecting adjacent property. The largest reductions were generally seen during the sprinklers tests with the highest flow rate. It was found that the baseline heat fluxes for the 4-m separation tests were similar to or even higher than the 3-m separation tests with the exception of the 2-MW tests. For the 2-MW fire the 3-m separation tests had clearly higher heat fluxes. This is believed to be caused by one or more reasons. The reasons include; the room used for the 4-m separation tests had better insulation resulting in more heat exiting from the opening, the separation distance between the compartment and the target wall may have affected the amount of air available to be entrained into the compartment, and variations in the propane flow rate.

The values of the façade wall heat fluxes were not stable initially due to the turbulence of the hot gases and flames escaping the compartment. The heat fluxes were found to be greater than the critical heat flux required for piloted ignition but were brought to acceptable levels with the introduction of the water curtain. The larger fires required larger flow rates to bring the heat fluxes down to acceptable levels. The use of sprinklers caused a decrease of the temperature of the hot gases and radiation heat fluxes. This can help prevent upward flame spread from a lower compartment to a higher one through an opening. The sensors closest to the opening were impacted more than the higher sensors due to being in closer proximity to the hot gases and flames that were exiting the compartment.

\section{DISCUSSION OF RESULTS}

In order to study the effect the water curtain had on attenuating radiation the individual fire tests were broken down and analyzed. For each test the configuration factor was determined using the height of the flames exiting the compartment as well as the sensors along the target wall that fell with the boundaries of the radiator area. The radiator was assumed to be rectangular and to be in plane with the window such that the window and flames exiting the compartment were a single rectangular radiator. The radiators for each test were broken down into quadrants and each configuration factor for the quadrants was determined. Using the individual quadrant configuration factors the total configuration factor for each test was determined. Once the configuration factors were determined the compartment temperatures for each test series was determined, shown in Table 7. 
Table 8. Calculated theoretical and experimental reduction factors.

\begin{tabular}{c|cc|cccc}
\hline & $57 \mathrm{~L} / \mathrm{min}$ & & $76 \mathrm{~L} / \mathrm{min}$ & \multicolumn{3}{c}{$91 \mathrm{~L} / \mathrm{min}$} \\
\hline & Calculated & Experimental & Calculated & Experimental & Calculated & Experimental \\
\hline Average Reduction & 21.82 & 23.23 & 29.91 & 31.18 & 37.59 & 38.55 \\
\hline
\end{tabular}

The average compartment temperatures were used to determine the theoretical reduction factor for each sensor using the following equations:

$$
\begin{aligned}
& q_{\text {red }}^{\prime \prime}=\left(1-f_{t}\right) \varphi \varepsilon \sigma\left(T_{c}^{4}-T_{a}^{4}\right) \\
& f_{t}=1-\left(\frac{q_{r}^{\prime \prime}}{\varphi \varepsilon \sigma\left(T_{c}^{4}-T_{a}^{4}\right)}\right) \\
& q_{r e d}^{\prime \prime}=\text { Experimental Reduced Heat Flux } \\
& f_{t}=\text { Theoretical Reduction Factor } \\
& \varphi=\text { Configuration Factor } \\
& \sigma=\text { Stefan Boltzmann constant }, 5.67 \times 10^{-8} \mathrm{~W} / \mathrm{m}^{2} \mathrm{~K}^{4} \\
& T_{e}=\text { Average Compartment Temperature, } \mathrm{K} \\
& T_{a}=\text { Ambient Temperature, } \mathrm{K} \\
& \varepsilon=\text { emissivity, } \varepsilon=\left(\frac{1}{\varepsilon_{e}}+\frac{1}{\varepsilon_{r}}-1\right)^{-1}
\end{aligned}
$$

Using Eq. (1) the reduction factor was solved for all sensors, fires, and flow rates. This theoretical reduction, Eq. (2), was then compared to the actual experimental reduction, Eq. (3), of the experimental heat fluxes with the water curtain to the baseline heat fluxes without the water curtain. Comparison of the calculated theoretical heat flux reductions and the actual experimental heat flux reductions found that the theoretical reductions were within $-8 \%$ to $4 \%$ of the actual experimental heat flux reductions.

$$
\begin{aligned}
& f_{e}=1-\frac{q_{r e d}^{\prime \prime}}{q_{\text {base }}^{\prime \prime}} \\
& q_{\text {red }}^{\prime \prime}=\text { Experimental Reduced Heat Flux } \\
& q_{\text {base }}^{\prime \prime}=\text { Experimental Baseline Heat Flux } \\
& f_{e}=\text { Experimental Reduction Factor. }
\end{aligned}
$$

The reductions were then averaged for each flow rate for both theoretical and experimental to determine the reduction factor for each particular flow rate, Table 8. The difference between the theoretical reduction factors and the experimental reduction factors is reasonably accurate with a difference of less than $1.5 \%$, which can be attributed to the use of ambient temperature instead of the actual temperature of the receiving surface. 


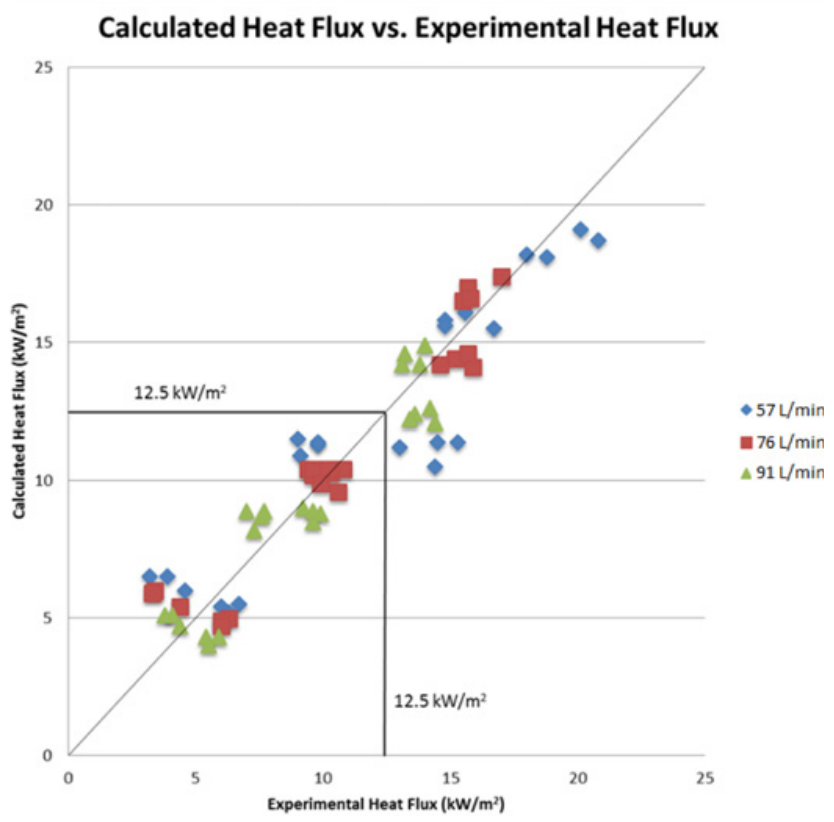

Figure 3. Calculated and experimental heat flux differences with critical heat flux displayed.

Using the average theoretical heat flux reductions the theoretical heat flux based on the reductions was calculated, using Eq. (4).

$$
\begin{aligned}
& q_{t}^{\prime \prime}=\left(1-f_{t}\right) \varphi \varepsilon \sigma\left(T_{c}^{4}-T_{a}^{4}\right) \\
& q_{t}^{\prime \prime}=\text { Theoretical Reduced Heat Flux } \\
& f_{t}=\text { Theoretical Reduction Factor } \\
& \varphi=\text { Configuration Factor } \\
& \sigma=\text { Stefan Boltzmann constant, } 5.67 \times 10^{-8} \mathrm{~W} / \mathrm{m}^{2} \mathrm{~K}^{4} \\
& T_{e}=\text { Average Compartment Temperature, } \mathrm{K} \\
& T_{a}=\text { Ambient Temperature, } \mathrm{K} \\
& \varepsilon=\text { emissivity, } \varepsilon=\left(\frac{1}{\varepsilon_{e}}+\frac{1}{\varepsilon_{r}}-1\right)^{-1} .
\end{aligned}
$$

The theoretical reduced heat flux was calculated using a reduction factor of $21.9 \%$ for the $57 \mathrm{~L} / \mathrm{min}$ flow rate, $29 \%$ for the $76 \mathrm{~L} / \mathrm{min}$ flow rate, and $39 \%$ for the $91 \mathrm{~L} / \mathrm{min}$ flow rate. The theoretical heat fluxes were then compared with the actual experimental heat fluxes for all sensors, fires, and flow rates. All the individual heat fluxes were compared and the average of the absolute differences was calculated. The average accuracy of the absolute differences was found to be within $18 \%$ for the $57 \mathrm{~L} / \mathrm{min}$ flow rate, $12 \%$ for the $76 \mathrm{~L} / \mathrm{min}$ flow rate, and $15 \%$ for the $91 \mathrm{~L} / \mathrm{min}$ flow rate. The individual differences were to some extent accurate with a few tests showing large inaccuracies but the overall accuracy is reasonable, Fig. 3. 


\section{MATEC Web of Conferences}

\section{CONCLUSIONS}

It was found that the reduction effect of the water curtain could be determined with reasonable accuracy such that it can be applied to the radiation equation to determine the reduced heat flux. When comparing the results of the theoretical and experimental reduced heat fluxes the average difference was less than $18 \%$ for the $2-\mathrm{MW}$ tests and less than $12 \%$ for the 3-MW tests and $15 \%$ for the $4-\mathrm{MW}$ tests. These findings can help establish guidelines for determining safe separation distances with the inclusion of a water curtain. With further study into the effectiveness of the water curtain the reduction factor can be modelled more effectively such that the reduction can be calculated using the flow rate and density of the water curtain.

Based on the experiments and research conducted in this thesis the following conclusions can be drawn:

1. For all tests the use of a water curtain was able to reduce the heat fluxes along the target wall to minimize the ignition of combustibles in adjacent properties.

2. For tests in which the heat fluxes were above the heat flux required for piloted ignition of wood the water curtain was wetting the target wall and preventing sparks from getting through to the target wall. This means that flame spread would not be possible without another flame source.

3. The water curtain was able to prevent upward flame spread by reducing the heat fluxes on the façade wall to within acceptable levels. The water curtain helps stabilize the turbulent flames and hot gases that were exiting the compartment and preventing the heat flux on the façade wall above the opening from reaching critical levels.

4. The piloted ignition of wood products criteria for the tests performed is a conservative value as the water curtain was preventing sparks from reaching the target wall. The water curtain was also wetting the target wall at close distances.

5. Heat flux and temperature reductions caused by the water curtain were found to be less effective as the separation distance increased.

6. The use of a water curtain lowered heat fluxes to allow for a reduced spatial separation requirements.

7. The effect of the water curtain on the attenuation of radiation can be modelled to within a reasonable accuracy based on the flow rate of the water curtain.

This research studied the ability of a water curtain placed over a compartment opening to attenuate radiation in order to protect adjacent property. The experiments conducted were on a single compartment with a single fixed opening. The factors that were tested included the flow rate of the water curtain, the fire sizes, and the separation distance. To ensure that the results of this research are used practically for assessing the performance of water curtains placed over compartment openings, further tests should be conducted using different compartment sizes and openings, as well as varying types of water curtains made with different sprinkler systems. In a building environment there are many possible parameters that could require different configurations that need to be studied.

In other areas of the world common construction materials may have different critical heat flux requirements. This research can be adjusted in order to compare reduced heat fluxes with critical heat fluxes of common construction materials, such as plastic cladding, in order to determine if a water curtain can be used as an effective fire protection system for other materials in those regions of the world. Comparison with building code requirements in those regions may allow for the installation of a water curtain to protect those materials.

Thanks to Ba Lamthien for assisting with construction and running the tests, and to the staff at the National Research Council of Canada's Fire Lab for their advice and help during these experiments. 
$2^{\text {nd }}$ International Seminar for Fire Safety of Facades, Lund (Sweden), 2016

\section{References}

[1] Shorter, G. W., et al. The St. Lawrence Burns. Division of Building Research, National Research Council, 1960.

[2] Law, Margaret. Heat radiation from fires and building separation. London: HM Stationery Office, 1963.

[3] Law, Margaret. Radiation from Fires in a Compartment. HM Stationery Office, 1968.

[4] Lin, Ching-Yuan. "Study of exposure fire spread between buildings by radiation." Journal of the Chinese institute of engineers 23.4 (2000): 493-504.

[5] Chen, A., and J. Francis. "Radiant heat flux to external surfaces from escaping and extrusive flashover flames." Proceedings of the Institution of Mechanical Engineers, Part C: Journal of Mechanical Engineering Science 217.2 (2003): 247-256.

[6] Cheng, Hao, and George V. Hadjisophocleous. "Experimental study and modeling of radiation from compartment fires to adjacent buildings." Fire Safety Journal 53 (2012): 43-62.

[7] Keramida, E. P., et al. "Numerical modeling of radiant heat attenuation through water mist." Combustion science and technology 159.1 (2000): 351-371.

[8] Coppalle, A., D. Nedelka, and B. Bauer. "Fire protection: water curtains." Fire Safety Journal 20.3 (1993): 241-255.

[9] Parent, Gilles, et al. "Experimental investigation of radiation transmission through a water spray." Journal of Quantitative Spectroscopy and Radiative Transfer 97.1 (2006): 126-141.

[10] Hostikka, Simo, and Kevin McGrattan. "Numerical modeling of radiative heat transfer in water sprays.” Fire Safety Journal 41.1 (2006): 76-86.

[11] Yang, Wenhua, et al. "The interaction of thermal radiation and water mist in fire suppression." Fire Safety Journal 39.1 (2004): 41-66.

[12] Boulet, Pascal, Anthony Collin, and Gilles Parent. "Heat transfer through a water spray curtain under the effect of a strong radiative source." Fire Safety Journal 41.1 (2006): 15-30.

[13] Tseng, C. C., and R. Viskanta. "Absorptance and transmittance of water spray/mist curtains." Fire safety journal 42.2 (2007): 106-114.

[14] Chow, Wan Ki, and Elaine YL Ma. "Experimental studies on thermal and smoke blockage by water curtains." 9th AIAA/ASME Joint Thermophysics and Heat Transfer Conference. 2006.

[15] Choi, C.L. "RADIATION BLOCKAGE EFFECTS BY WATER CURTAIN." International Journal on Engineering Performance-Based Fire Codes, 6, 4 (2004): P.248-254.

[16] Kim, Sung Chan, and Hong Sun Ryou. "An experimental and numerical study on fire suppression using a water mist in an enclosure." Building and Environment 38.11 (2003): 1309-1316.

[17] Grant, G., J. Brenton, and D. Drysdale. "Fire suppression by water sprays."Progress in energy and combustion science 26.2 (2000): 79-130.

[18] Buchlin, Jean-Marie. "Thermal shielding by water spray curtain." Journal of loss prevention in the process industries 18.4 (2005): 423-432. 